\title{
Severe blood loss anaemia and recurrent intussusceptions as first presentation of bowel metastatic renal cell carcinoma: A case report and review of the literature
}

\author{
CLAUDIA TROJANIELLO ${ }^{1}$, MARIA GIUSEPPA VITALE ${ }^{2}$, BIAGIO TROJANIELLO ${ }^{3}$, MARIA LUISA LENTINI GRAZIANO ${ }^{1}$, \\ MARIAROSA COCCARO ${ }^{1}$, GIACOMO CARTENI ${ }^{2}$ and VINCENZO MONTESARCHIO ${ }^{1}$ \\ ${ }^{1}$ Oncology Unit, Azienda Ospedaliera dei Colli, Ospedale Monaldi; ${ }^{2}$ UOSC Oncologia Medica, \\ Azienda Ospedaliera di Rilievo Nazionale 'Antonio Cardarelli'; ${ }^{3}$ U.O. Urgenze Chirurgiche ed \\ Accettazione Generale, Ospedale San Paolo ASL Napoli 1 Centro, I-80131 Naples, Italy
}

Received October 22, 2016; Accepted February 14, 2017

DOI: $10.3892 /$ mco.2017.1365

\begin{abstract}
Renal cell carcinoma (RCC) may metastasize to almost any organ, but bowel metastases are highly unusual. A 75-year-old man presented with symptoms and signs of severe anaemia due to bowel bleeding and abdominal pain due to recurrent bowel intussusception. The patient underwent surgery and was identified to have intraluminal metastases from metastatic RCC. To the best of our knowledge, few cases of metastases from RCC manifesting as synchronous intraluminal polypoid tumours have been described in the literature. The present report focused on the importance of two aspects that must be considered: The role of accurate diagnosis and of surgery treating intestinal metastases that may lead to symptom control and prolonged survival.
\end{abstract}

\section{Introduction}

Renal cell carcinoma (RCC) is a common malignancy, of which there were $\sim 12,600$ cases in 2015 in Italy (1). It represents $3 \%$ of all adult malignancies in this region, and is the third most frequent urologic malignancy after prostate and bladder cancer (2). RCC accounts for $90 \%$ of kidney cancer cases, and $\sim 80 \%$ of these are clear cell carcinomas $(3,4)$. The majority of cases of renal cancer are asymptomatic and are diagnosed incidentally, due to more extensive use of diagnostic

Correspondence to: Dr Claudia Trojaniello, Oncology Unit, Azienda Ospedaliera dei Colli, Ospedale Monaldi, Via Leonardo Bianchi 1, I-80131 Naples, Italy

E-mail: claudia.trojaniello@gmail.com

Dr Maria Giuseppa Vitale, UOSC Oncologia Medica, Azienda Ospedaliera di Rilievo Nazionale 'Antonio Cardarelli', Via Antonio Cardarelli 9, I-80131 Naples, Italy

E-mail: vitalemariag@gmail.com

Key words: renal cell cancer, metastases, small bowel, anaemia, bleeding, intussusceptions, surgery imaging, whereas the classic triad of haematuria, flank pain and palpable abdominal mass are rarely the first symptoms of presentation, occurring in $4-17 \%$ of cases $(5,6)$.

On occasion, the symptoms occurring due to the presence of intestinal metastasis may be the first presentation of renal cancer $(7,8)$. These symptoms usually include nausea, abdominal pain, intussusception, weight loss, melena, bowel perforation, and primarily, gastrointestinal bleeding caused by the infiltration of intestinal vessels (9).

The current study presents the case of a 75-year old male in which severe anaemia due to bowel bleeding and abdominal pain from recurrent bowel intussusceptions were the first presentations of metastatic renal cell carcinoma. A review of the cases of bowel metastasis from renal cell carcinoma described in the literature from 2006 to the present was also conducted (Table I). Written informed consent was obtained from the patient for the publication of this case report and accompanying images.

\section{Case presentation}

In February 2014, a 75-year old male presented to San Paolo Hospital (Naples Italy) emergency department with symptoms and signs of severe anaemia: Tachycardia, pallor, fatigue and hypotension. The patient's medical history was relevant for chronic gastritis, prostate cancer, diabetes mellitus and Parkinson's disease, recurrent abdominal pain and constipation. Laboratory tests revealed severe anaemia (haemoglobin level, $5.6 \mathrm{~g} / \mathrm{dl}$, normal range $14-18 \mathrm{~g} / \mathrm{dl}$ ) that required a transfusion of packed red blood cells. At rectal examination, tarry stools compatible with melena were evident and an esophagogastroduodenoscopy was performed, but was negative for bleeding lesions. Abdominal ultrasound revealed the presence of a lesion of $35 \mathrm{~mm}$ in the lower pole of the left kidney suspicious for a neoplastic lesion and thickening of the bowel loops into the abdomen centre. These findings were further detailed with a total body computerized tomography (CT) scan that confirmed the neoplastic lesion of the left kidney and revealed thickening of the wall of the jejunal loops with target lesions. 
The CT scan revealed the requirement for a colonoscopy, which was negative. During hospitalization, numerous red blood transfusions were required for the persistence and worsening of anaemia. Technetium-labelled erythrocyte scintigraphy was performed to localize the site of acute gastrointestinal bleeding. It exhibited accumulation in proximity to the lower pole of the right kidney extending to the right iliac fossa for peristaltic transportation; these findings identified the jejunal loops as the source of bleeding (Fig. 1).

Therefore, the patient underwent an exploratory laparotomy, which determined multiple jejuno-jejunal intussusceptions with a number of pedunculated polypoid formations that occupied all the jejunum, with dimensions ranging between 1 and $8 \mathrm{~cm}$. There was also a pedunculated polypoid formation in the distal ileum. A small neoplastic lesion of the lower pole of the left kidney was identified using palpation. Resection of the jejunum with side- to-side anastomosis was performed. The postoperative course was uneventful without complications.

Macroscopic examination of the jejunal segment revealed 23 polyps, covered with eroded mucosa (the largest measuring $8 \times 5 \mathrm{~cm}$ ), with a yellow-grey colour when dissected (Fig. 2). Histopathology tests revealed cellular elements with abundant eosinophilic cytoplasm, atypical nuclei with aspects of signet ring cell, atypical mitotic figures and angioinvasion, which were positive for cytokeratin, vimentin and Wilms cancer protein. The definitive diagnosis was metastases from high-grade renal cell carcinoma. Metastases were also identified in 5/40 removed lymph nodes. The patient was discharged 10 days after surgery without any complications. The multidisciplinary team decided to begin only best supportive care, due to the patient's comorbidity, old age and poor performance status. The patient succumbed to mortality in December 2014, nine months following surgery.

\section{Discussion}

Between 25 and $30 \%$ of patients are found to have metastases at diagnosis, and a further $30-50 \%$ of patients with local disease will develop metastases during the course of their illness (10). Approximately $60 \%$ of kidney cancer cases are diagnosed incidentally, as a direct result of the more extensive use of diagnostic imaging in patients not suspected for renal cancer $(11,12)$.

The sizes of primary tumours are not associated with the risk of metastasis. The major sites of kidney cancer metastasis are lung (75\%), bone (20\%), lymph nodes (11\%), liver $(18 \%)$, and brain (8\%) but virtually all organs may be affected (7). However, intestinal metastasis is rare and usually occurs when there is widespread dissemination of the primary cancer. In the current case, bowel metastases were the only site of metastases from RCC. The present study examined the literature for cases of bowel metastasis from RCC published from 2006 to present, and identified 24 case reports (Table I).

Symptoms of bowel metastases from RCC usually include nausea, abdominal pain, intussusception, weight loss, melena, bowel perforation (9) gastrointestinal bleeding (due to the invasion of the intestinal vessels by the disease), which in the reported cases represented $\sim 55.6 \%$ of the onset of manifestations of intestinal metastasis from RCC, and symptoms of intestinal obstruction due to the presence of a mass within the intestinal wall (12), which in the current review was found to be present in $50 \%$ of patients.

However, there is a delay in diagnosis in the identification of metastases to the small intestine. Certain patients with gastrointestinal bleeding remain undiagnosed even following upper endoscopy and colonoscopy in, as these regions are challenging to access for diagnosis (13) and traditional methods of investigating the small intestine such as barium follow-through and CT have a low yield for cancer detection. Abdominal CT is only able to reveal a thickening of the intestinal wall and a fold in the intestine (14), and is frequently unable to determine the cause, as in the present review, in which the diagnosis of metastases to the small intestine is performed in $65 \%$ of cases.

Diagnosis of small bowel metastasis in RCC is most frequently performed by upper enteroscopy with tissue sampling, where the lesion can be detected as an ulcer, submucosal mass with ulceration or multiple nodules or small polyps of varying sizes (15). Capsule endoscopy (CE) is a simple, safe, and comfortable diagnostic technique, but does not allow biopsies and it is not performed when intussusception is suspected. On the other hand, double balloon enteroscopy (DBE) is a useful method for histological confirmation of small bowel lesions. Using the combination of CE and DBE, it is possible to obtain clear endoscopic images of the lesions and histological diagnosis prior to the patient undergoing surgery. CE is a reliable approach to such screening, and DBE is an effective approach to the histological diagnosis of small intestinal neoplasms $(16,17)$.

The duration of the interval between initial nephrectomy and presentation of intestinal metacronous metastases ranges from 3 months to 20 years, and correlates with overall survival $(12,18-20)$. The mean time from nephrectomy to metastatic recurrence is 8 years, and $\sim 11 \%$ of metastases occur after $\geq 10$ years (21). Few cases of renal cancer present with synchronous bowel metastasis, including the current case.

Small bowel intraluminal metastases from renal cell cancer are unusual (2-4\%) (22) and autopsy cases revealed an incidence of $0.7-14.6 \%(23,24)$. Several mechanisms may be hypothesized including: Peritoneal dissemination, direct spread from an intra-abdominal malignancy, haematogenous and lymphatic spread (25). Haematogenous dissemination from the pulmonary circulation appears to have an important role in the metastatic spread of RCC to the intestine (26) and the majority of patients with intestinal metastases have lung involvement (9).

Males are more commonly affected (male: female=1.5:1) and the incidence of metastasis from RCC increases with age (12). In the current review, males were more commonly affected (22 M vs. 4F; ratio 5:1). The mean age at diagnosis of metastasis was 61 years (median age, 61; range, 32-86 years). The possible aetiology of extensive small bowel metastasis presenting as polyposis, may be transient showering of multiple tumour emboli in the celiac and mesenteric arteries (17). The cases of isolated intestinal metastases were rare, and generally the metastases are also present in other organs (27) In the case of right-sided RCC, the probability of duodenal metastasis is always higher due to the greater risk of loco-regional invasion (28). Intestinal metastases occur equally in the jejunum and the ileum (usually present 


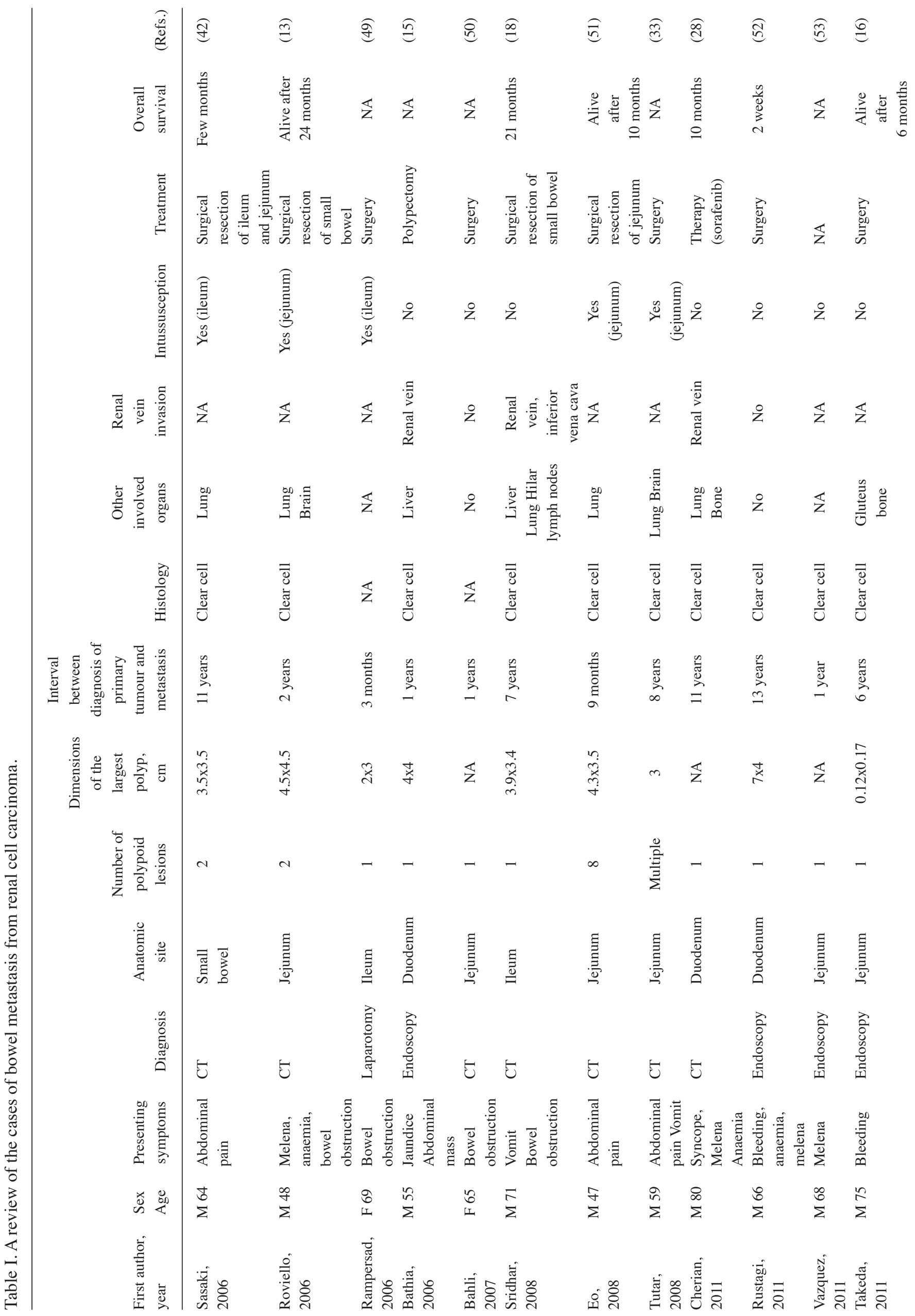




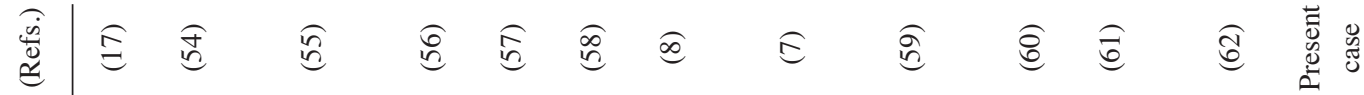

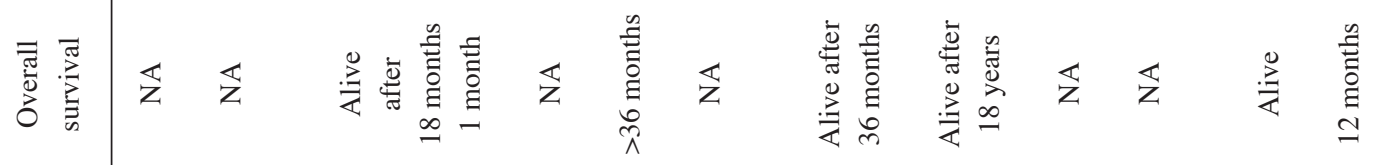

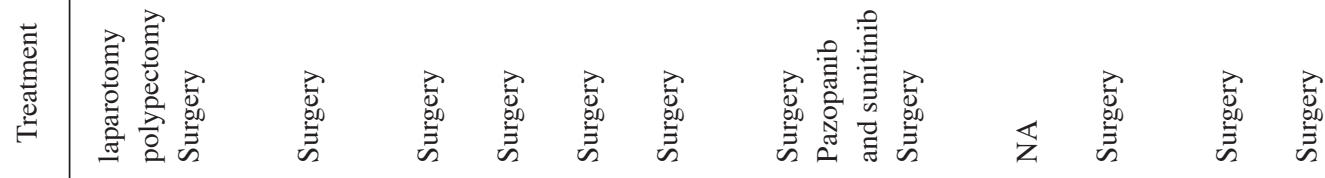

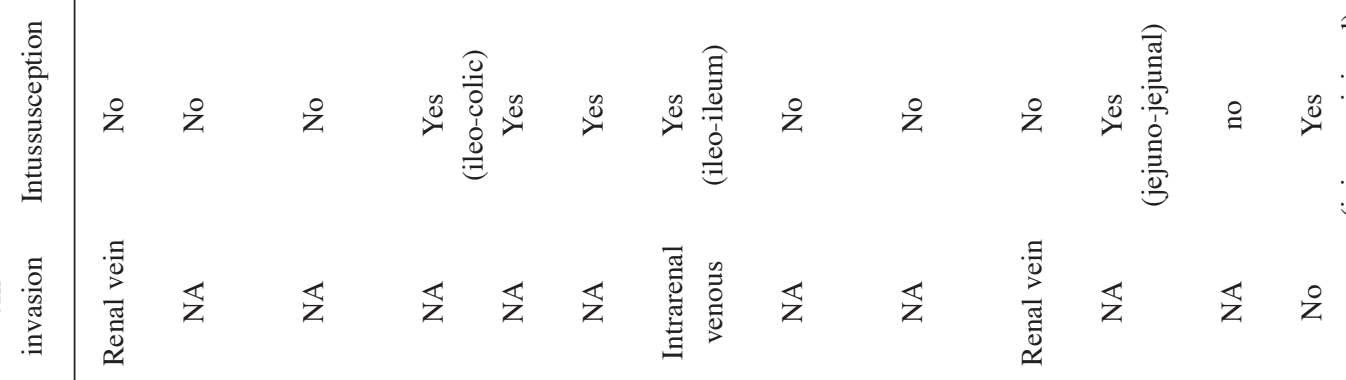

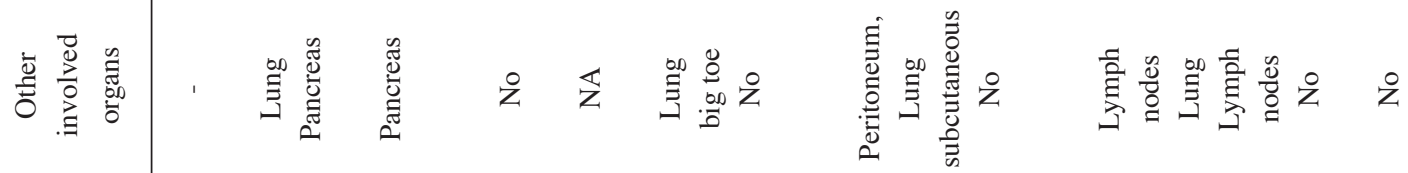

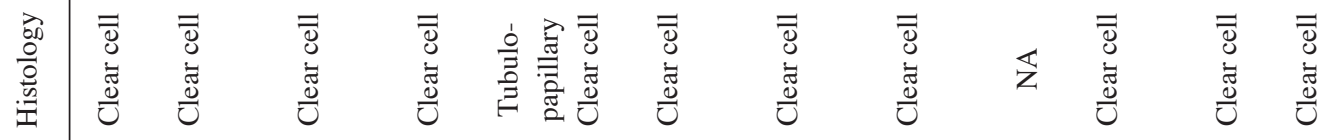

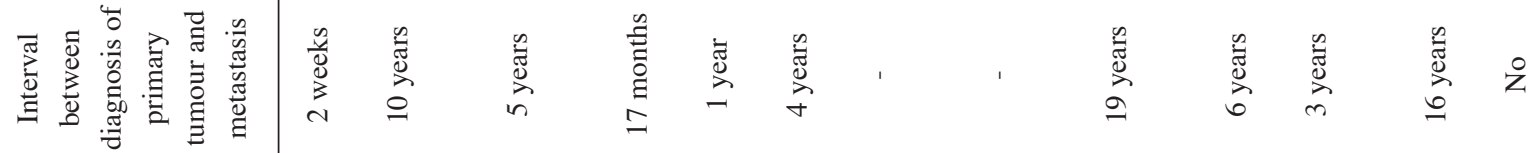

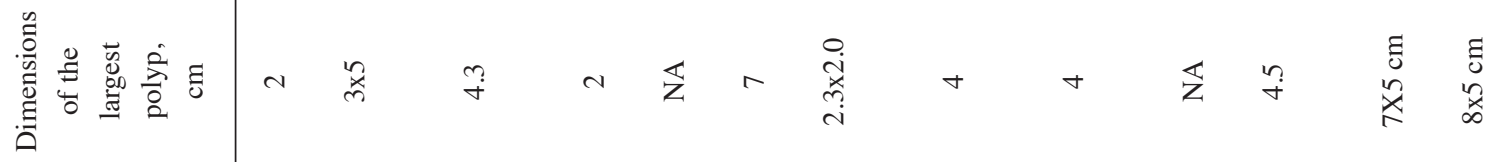

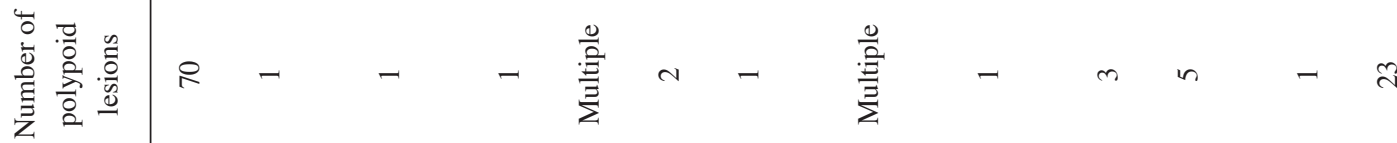

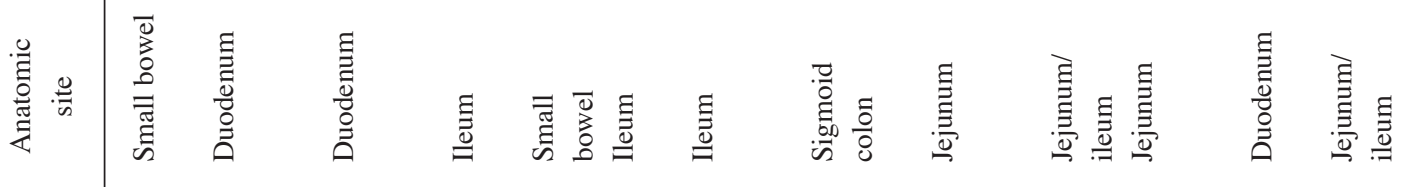

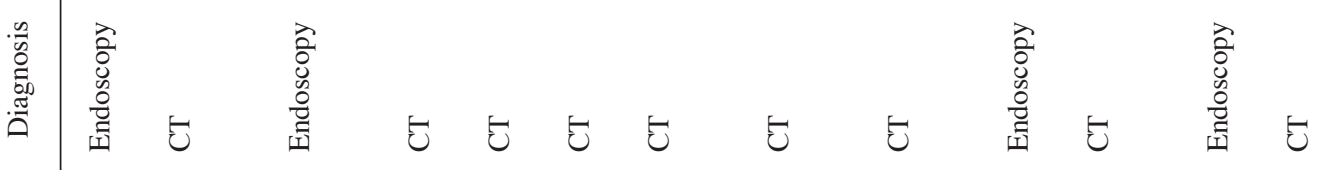

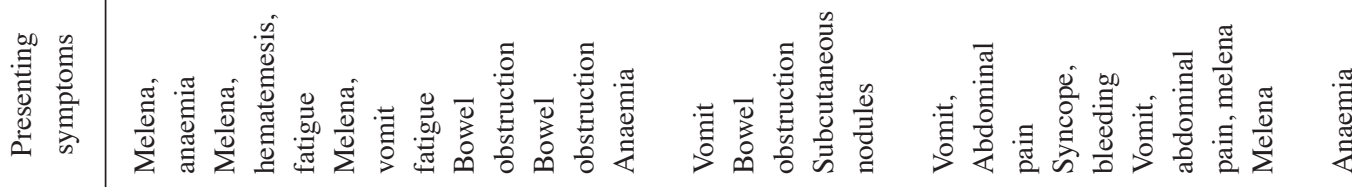

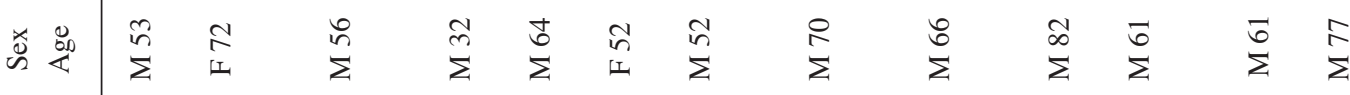

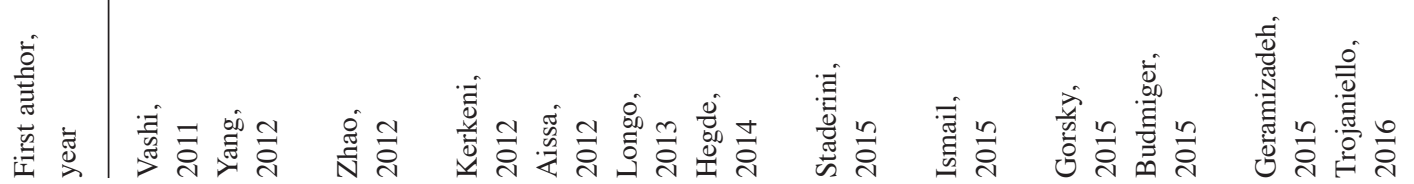

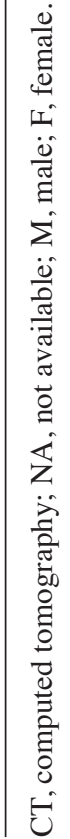



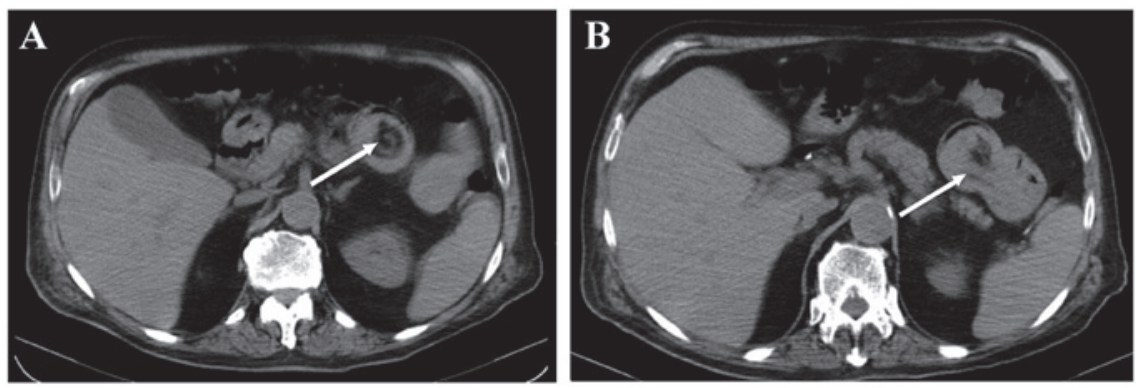

Figure 1. (A) Axial-enhanced CT scan of the abdomen illustrating a jejunal intussusception, visible as a target-shaped lesion with a lead point (arrow). (B) Axial-enhanced CT of the abdomen illustrating a jejunal intussusception, visible as a target-shaped lesion with a lead point (arrow). CT, computed tomography.

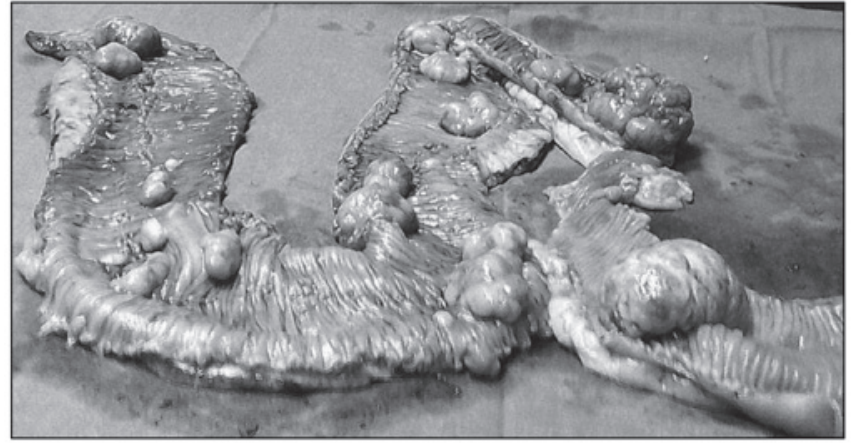

Figure 2. Macroscopic examination of the jejunal segment revealed 23 polyps covered with eroded mucosa. The largest size detected was $8 \times 5 \mathrm{~cm}$.

with intestinal bleeding due to tumoral invasion of intestinal vessels) (18); however, certain studies, including 38\% of those reviewed in the current study, indicate the jejunum as the most frequent area of intestinal metastases (13). In the present review, only one case of metastasis to the colon sigmoid was identified. The average number of metastatic intestinal polyps usually present as a result of RCC is 2 (as is evidenced in our review); the only 2 cases that have been reported in the literature for 10 years to date are the case report of Vashi et al (17) with 70 polyps and the current case with 23 polyps, of which the largest was $8 \times 5 \mathrm{~cm}$ in size, the largest detected in any of the reviewed cases.

The most suitable treatment for metastases of the small intestine from RCC remains controversial, and is dependent on several factors, including clinical conditions, comorbidities, free interval between nephrectomy and metastasis, the number, location and resectability of metastases (29). Surgery must be considered not only to palliate symptoms, but also as it may lead to improved overall survival (30). In fact, the complete removal of secondary lesions aids the improvement of the prognosis of patients with metastatic RCC (30). A recent retrospective case series has revealed a benefit in terms of cancer specific survival (CSS) in favour of the complete resection of metastases (CSS, 4.8 vs. 1.3 years) regardless of the sites of disease and time of onset (30). The patient in the current case report did not undergo radical surgery of metastatic lesions due to distant locations; however, surgery was performed to control the complication of bowel bleeding.

On occasion, symptoms of metastases from RCC presentations are secondary to the phenomena of sub-occlusion/ occlusion due to the phenomenon of intussusception, which is rare in adults and accounts for $1 \%$ of all bowel obstruction cases (31). Intussusceptions are more frequent in the jejunum and ileum, and detection of an intestinal intussusception in patients with RCC must always raise suspicion of a secondary metastasis in the small intestine $(32,33)$. The management of adult intussusception remains controversial; however, metastasectomy may extend patient survival (34). Therefore, surgical resection of the involved intestinal segment has been recommended as the treatment of choice $(35,36)$. The diagnosis of intussusception is complex, but in the majority of cases CT allows the diagnosis of the presence of an intraluminal soft-tissue density within the lumen of the bowel, the intussuscepted hernia, referred to as the 'target' sign, which is associated with the presence of eccentric mesenteric fat and vessels and is considered a pathognomonic sign of intussusception on CT images (37).

Other authors instead identify other equally valid diagnostic methods, including barium enema, abdominal ultrasound, plain film X-rays and radionucleotide studies (38-40) and colour Doppler ultrasound may be used to evaluate the vascularity of the intussusception and to predict bowel viability (41). However, the diagnosis can be too challenging to determine preoperatively, and is performed only during the surgical examination. Colonoscopy and sigmoidoscopy are usually nondiagnostic (19).

At present, there have been few case reports detailing intussusceptions of the small intestine secondary to RCC (19,42-46), with only one another case (in addition to the present case) of multiple intussusception of the small intestine (19). Unlike in children, intussusceptions in adults are more often associated with underlying diseases (47). Intussusceptions may develop either from the small or the large intestine, but the aetiology is variable. Intussusception of the small intestine is usually secondary to benign lesions, whereas those of the large intestine are more frequently associated with malignant lesions $(47,48)$.

Patients who are not candidates for radical resection of metastatic lesions must be treated with targeted therapy. The standard first line treatment for metastatic renal cell carcinoma is bevacizumab (combined with interferon- $\alpha$ ), sunitinib or pazopanib for patients with good or intermediate prognosis and temsirolimus or sunitinib for patients with poor prognosis. The choice of treatment must account for the characteristics of the disease (tumour burden and histotype), 
of patients (performance status, age, comorbidities) and drug safety. In the current case, the patient was not candidate for first line treatment due to comorbidity, age and poor performance status.

In conclusion, the present case report highlights the importance of vigilance and a high index of suspicion in patients with renal cancer history upon presentation of new clinical symptoms. Appropriate awareness, recognition and aggressive work-up of gastrointestinal symptoms in these patients are of paramount importance. This case report focuses on two aspects that must be considered. Firstly, an accurate diagnosis must be obtained upon presentation of a particular sign/symptom, in this case anaemia. The present study recommends investigating the possibility of small intestinal metastases in cases of intestinal bleeding or anaemia with iron deficiency in patients with a history of malignant tumour, using endoscopy or CT. Secondly, based on clinical conditions and comorbidities and following an accurate tumour staging, it is important to identify the potential for a radical resection of intestinal metastases that may lead to symptom control and to a prolonged survival, particularly if an active therapy is possible.

\section{References}

1. I numeri del cancro in Italia 2014. www.registri-tumori.it

2. Maldazys JD and deKernion JB: Prognostic factors in metastatic renal carcinoma. J Urol 136: 376-379, 1986.

3. Moch H, Gasser T, Amin MB, Torhorst J, Sauter G and Mihatsch MJ: Prognostic utility of the recently recommended histologic classification and revised TNM staging system of renal cell carcinoma: A Swiss experience with 588 tumors. Cancer 89: 604-614, 2000

4. Leibovich BC, Lohse CM, Crispen PL, Boorjian SA, Thompson RH, Blute ML and Cheville JC: Histological subtype is an independent predictor of outcome for patients with renal cell carcinoma. J Urol 183: 1309-1315, 2010.

5. Waters WB and Richie JP: Aggressive surgical approach to renal cell carcinoma: Review of 130 cases. J Urol 122: 306-309, 1979.

6. Griffiths LH and Thackray AC: Parenchymal carcinoma of the kidney. Br J Urol 21: 128-151, 1949.

7. Staderini F, Cianchi F, Badii B, Skalamera I, Fiorenza G, Foppa C, Qirici E and Perigli G: A unique presentation of a renal clear cell carcinoma with atypical metastases. Int J Surg Case Rep 11: 29-32, 2015

8. Hegde RG, Gowda HK, Agrawal RD, Yadav VK and Khadse GJ: Renal cell carcinoma presenting as small bowel obstruction secondary to a metastatic ileal intussusception. J Radiol Case Rep 8: 25-31, 2014.

9. Nozawa H, Tsuchiya M, Kobayashi T, Morita H, Kobayashi I, Sakaguchi M, Mizutani T, Tajima A, Kishida Y, Yakumaru K, et al: Small intestinal metastasis from renal cell carcinoma exhibiting rare findings. Int J Clin Pract 57: 329-331, 2003

10. Pavlakis GM, Sakorafas GH and Anagnostopoulos GK: Intestinal metastases from renal cell carcinoma: A rare cause of intestinal obstruction and bleeding. Mt Sinai J Med 71: 127-130, 2004.

11. Klatte T, Patard JJ, de Martino M, Bensalah K, Verhoest G, de la Taille A, Abbou CC, Allhoff EP, Carrieri G, Riggs SB, et al: Tumor size does not predict risk of metastatic disease or prognosis of smal renal cell carcinomas. J Urol 179: 1719-1726, 2008

12. Decastro GJ and McKiernan JM: Epidemiology, clinical staging, and presentation of renal cell carcinoma. Urol Clin North Am 35: 581-592; vi, 2008

13. Roviello F, Caruso S, Moscovita Falzarano S, Marrelli D, Neri A, Rampone B, De Marco G, Perrotta ME and Mariani F: Small bowel metastases from renal cell carcinoma: A rare cause of intestinal intussusception. J Nephrol 19: 234-238, 2006.

14. Honda W, Ohmiya N, Hirooka Y, Nakamura M, Miyahara R, Ohno E, Kawashima H, Itoh A, Watanabe $\mathrm{O}$, Ando $\mathrm{T}$ and Goto H: Enteroscopic and radiologic diagnoses, treatment, and prognoses of small-bowel tumors. Gastrointest Endosc 76: 344-354, 2012 .
15. Bhatia A, Das A, Kumar Y and Kochhar R: Renal cell carcinoma metastasizing to duodenum: A rare occurrence. Diagn Pathol 1: 29, 2006.

16. Takeda T, Shibuya T, Osada T, Izumi H, Mitomi H, Nomura O, Suzuki S, Mori H, Matsumoto K, Kon K, et al: Metastatic renal cell carcinoma diagnosed by capsule endoscopy and double balloon endoscopy. Med Sci Monit 17: CS15-CS17, 2011.

17. Vashi PG, Abboud E and Gupta D: Renal cell carcinoma with unusual metastasis to the small intestine manifesting as extensive polyposis: Successful management with intraoperative therapeutic endoscopy. Case Rep Gastroenterol 5: 471-478, 2011.

18. Sridhar SS, Haider MA, Guindi M and Moore MJ: A case of small bowel obstruction due to intraluminal metastases from metastatic renal cell cancer. Oncologist 13: 95-97, 2008.

19. Deguchi R, Takagi A, Igarashi M, Shirai T, Shiba T, Watanabe S, Kurumada T, Miwa T, Sadahiro S and Yasuda M: A case of ileocolic intussusception from renal cell carcinoma. Endoscopy 32: 658-660, 2000.

20. Van der Poel HG, Roukema JA, Horenblas S, van Geel AN and Debruyne FM: Metastasectomy in renal cell carcinoma: A multicenter retrospective analysis. Eur Urol 35: 197-203, 1999.

21. Adamo R, Greaney PJ Jr, Witkiewicz A, Kennedy EP and Yeo CJ: Renal cell carcinoma metastatic to the duodenum: Treatment by classic pancreaticoduodenectomy and review of the literature. J Gastrointest Surg 12: 1465-1468, 2008.

22. Farthouat P, Faucompret S, Louis C, Debourdeau P, Pero C and Breda Y: Gastrointestinal hemorrhage due to jejunal metastases from kidney cancer. Ann Chir 125: 797-798, 2000.

23. DeCastro CA, Dockerty MB and Mayo CW: Metastatic tumors of the small intestines. Surg Gynecol Obstet 105: 159-165, 1957.

24. Saitoh H, Nakayama M, Nakamura K and Satoh T: Distant metastasis of renal adenocarcinoma in nephrectomized cases. J Urol 127: 1092-1095, 1982.

25. Loualidi A, Spooren PF, Grubben MJ, Blomjous CE and Goey SH: Duodenal metastasis: An uncommon cause of occult small intestinal bleeding. Neth J Med 62: 201-205, 2004.

26. Saitoh H: Distant metastasis of renal adenocarcinoma. Cancer 48 : 1487-1491, 1981

27. Smith SJ, Carlson HC and Gisvold JJ: Secondary neoplasms of the small bowel. Radiology 125: 29-33, 1977.

28. Cherian SV, Das S, Garcha AS, Gopaluni S, Wright J and Landas SK: Recurrent renal cell cancer presenting as gastrointestinal bleed. World J Gastrointest Oncol 3: 99-102, 2011.

29. Herrans AF, Diez CJ, Garcìa BJ: "Factores pronósticos en el adenocarcinoma de riñón”. Tumores de riñón. Ediciones Doyma. Madrid, 2001.

30. Alt AL, Boorjian SA, Lohse CM, Costello BA, Leibovich BC and Blute ML: Survival after complete surgical resection of multiple metastases from renal cell carcinoma. Cancer 117: 2873-2882, 2011.

31. Coleman MJ, Hugh TB, May RE and Jensen MJ: Intussusception in the adult. Aust N Z J Surg 51: 179-181, 1981.

32. Karahan N, Bozkurt KK, Cırıș IM, Songür Y, Akin M, Cetın M and Koşar A: Duodenojejunal invagination caused by small bowel metastasis of renal cell carcinoma. Turk J Gastroenterol 22: 355-357, 2011.

33. Tutar NU, Töre HG, Aydin HM, Geyik E, Coskun M and Niron EA: Case report: Jejuno-jejunal nvagination from metastatic renal cell carcinoma. Br J Radiol 81: e115-e117, 2008.

34. Venugopal A, Mahesh S, Lekha V, Jacob G, Gandhi MD, Bedi MM, Sharma M, Jacob M and Ramesh H: Intussusception due to ileal metastases from renal cell carcinoma. Trop Gastroenterol 28: 35-36, 2007.

35. Tolia BM and Whitmore WF Jr: Solitary metastasis from renal cell carcinoma. J Urol 114: 836-838, 1975.

36. Eo WK, Kim GY and Choi SI: A case of multiple intussusceptions in the small intestine caused by metastatic renal cell carcinoma. Cancer Res Treat 40: 97-99, 2008.

37. Gayer G, Zissin R, Apter S, Papa M and Hertz M: Pictorial review: Adult intussusception-a CT diagnosis. Br J Radiol 75: 185-190, 2002.

38. Bar-Ziv J and Solomon A: Computed tomography in adult intussusception. Gastrointest Radiol 16: 264-266, 1991.

39. Iko B, Teal J, Siram SM, Chinwuba CE, Roux VJ and Scott VF: Computed tomography of adult colonic intussusception: Clinical and experimental studies. AJR Am J Roentgenol 143: 769-772, 1984

40. Montali G, Croce F, De Pra L and Solibiati L: Intussusception of the bowel: A new sonographic pattern. Br J Radiol 56: 621-623, 1983. 
41. Verschelden P, Filiatrault D, Garel L, Grignon A, Perreault G, Boisvert $\mathrm{J}$ and Dubois J: Intussusception in children: Reliability of US in diagnosis-a prospective study. Radiology 184: 741-744, 1992.

42. Sasaki M, Murakami Y, Takesue Y, Yokoyama Y, Morifuji M, Hayashidani Y, Koyama M and Sueda T: Double intussusceptions in the small intestine caused by metastatic renal cell carcinoma: Report of a case. Surg Today 36: 85-88, 2006.

43. Johnson WA and Straus FH: Intussusception of the small intestine produced by metastatic renal carcinoma. Surgery 32 991-996, 1952.

44. Haynes IG, Wolverson RL and O'Brien JM: Small bowel intussusception due to metastatic renal carcinoma. Br J Urol 58: 460, 1986.

45. Khan AB: Ileocaecal intussusception due to metastatic renal carcinoma. Br J Urol 67: 657-658, 1991.

46. Savoye-Collet C, Thoumas D, Dunet F, Lemercier E and Benozio $\mathrm{M}$ and Dacher JN: CT diagnosed jejunal intussusception revealing metastatic renal cell carcinoma. JBR-BTR 84: 153-154, 2001.

47. Gayer G, Zissin R, Apter S, Papa M and Hertz M: Pictorial review: Adult intussusception-a CT diagnosis. Br J Radiol 75: 185-190, 2002

48. Begos DG, Sandor A and Modlin IM: The diagnosis and management of adult intussusception. Am J Surg 173: 88-94, 1997.

49. Rampersad RD, Ramcharan R and Maharaj D: Small bowe intussusception: A rare complication of renal cell carcinoma. West Indian Med J 55: 68-69, 2006

50. Bahli ZM and Panesar KJ: Solitary jejunal metastasis from renal cell carcinoma. J Ayub Med Coll Abbottabad 19: 62-63, 2007.

51. Eo WK, Kim GY and Choi SI: A case of multiple intussusceptions in the small intestine caused by metastatic renal cell carcinoma. Cancer Res Treat 40: 97-99, 2008.

52. Rustagi T, Rangasamy P and Versland M: Duodenal Bleeding from metastatic renal cell carcinoma. Case Rep Gastroenterol 5: 249-257, 2011.
53. Vazquez C, Berrueta J, De Simone F, Tcheckmedyian A, Gonzalez N, Bernachin J, Perrota A, Curi J, Mariño A and Olano C: Small-intestinal bleeding due to metastatic renal cell cancer. Endoscopy 43 (Suppl 2): UCTN:E13, 2011.

54. Yang J, Zhang YB, Liu ZJ, Zhu YF and Shen LG: Surgical treatment of renal cell carcinoma metastasized to the duodenum. Chin Med J 125: 3198-3200, 2012.

55. Zhao H, Han K, Li J, Liang P, Zuo G, Zhang Y and Li H: A case of wedge resection of duodenum for massive gastrointestinal bleeding due to duodenal metastasis by renal cell carcinoma. World J Surg Oncol 10: 199, 2012.

56. Kerkeni W, Bouzouita A, Jarraya H, Selmi MS, Cherif M, Derouich A, Kourda N, Dziri C, Zermani R, Ben Slama MR and Chebil M: Ileocolic intussusception from metastatic renal cell carcinoma. Prog Urol 23: 73-75, 2013 (In French).

57. Aissa A, Kherifech M, Alouini R, Hajji H and Stita W: Multiple intussusceptions revealing metastases from renal carcinoma to the small intestine. J Visc Surg 149: e223-e224, 2012.

58. Longo R, Gattuso D, Luchetti R, Giannetti C, Mero A, Bernardi C and Gasparini G: Atypical multiple ileum metastases of renal cell carcinoma. J Gastrointest Cancer 44: 477-480, 2013.

59. Ismail I, Neuen BL and Mantha M: Solitary jejunal metastasis from renal cell carcinoma presenting as small bowel obstruction 19 years after nephrectomy. BMJ Case Rep: pii: bcr2015210857, 2015

60. Gorski RL, Jalil SA, Razick M and Jalil AA: An obscure cause of gastrointestinal bleeding: Renal cell carcinoma metastasis to the small bowel. Int J Surg Case Rep 15: 130-132, 2015.

61. Budmiger MA, Nagy V, Hürlimann S and Metzger J: Triple jejuno-jejunal intussusception due to metastatic renal cell carcinoma. J Surg Case Rep 2015: pii: rjv047, 2015.

62. Geramizadeh B, Mostaghni A, Ranjbar Z, Moradian F, Heidari M and Khosravi MB: An unusual case of metastatatic renal cell carcinoma presenting as melena and duodenal ulcer, 16 years after nephrectomy; a case report and review of the literature. Iran J Med Sci 40: 175-180, 2015. 